\title{
Psychological well-being among US adults with arthritis and the unmet need for mental health care
}

\author{
Laura E Straub ${ }^{1,2}$ \\ Miriam G Cisternas ${ }^{3}$ \\ 'Emory University, Atlanta, GA, \\ ${ }^{2}$ Immune Tolerance Network, San \\ Francisco, CA, ${ }^{3}$ MGC Data Services, \\ Carlsbad, CA, USA
}

This article was published in the following Dove Press journal:

Open Access Rheumatology: Research and Reviews

II May 2017

Number of times this article has been viewed
Purpose: Mental health conditions can increase the risk of disability among adults with arthritis. The objective of this analysis was to compare the prevalence of serious psychological distress (SPD), depression, and anxiety among US adults with arthritis vs. those without; characterize adults with arthritis with and without SPD; and determine correlates of seeing a mental health professional during the year for adults with arthritis and SPD.

Materials and methods: Cross-sectional analysis of adults in the 2011-2013 National Health Interview Survey.

Results: Higher proportions of adults with arthritis had SPD (6.8\% vs. 2.4\%), depression ( $19.4 \%$ vs. $7.3 \%$ ), and anxiety ( $29.3 \%$ vs. $16.3 \%$ ) compared to those without. Of the estimated 3.5 million adults with arthritis and SPD, only $39 \%$ saw a mental health professional during the year. Adjusted analyses identified the following statistically significant relationships: those who were older (45-64 and $\geq 65$ [vs.18-44], prevalence ratio [PR] $=0.8$ and 0.4 , respectively), less educated ( $\mathrm{PR}=0.5$ and 0.7 for high school or less vs. college degree, respectively), and without health insurance coverage (vs. any private, $\mathrm{PR}=0.7$ ), were less likely to see a mental health professional, whereas the disabled or unemployed (vs. employed, $\mathrm{PR}=1.6$ and 1.5, respectively), and those unable to afford mental health care throughout the year $(\mathrm{PR}=1.3)$ were more likely.

Conclusion: The high prevalence of SPD, anxiety, and depression in adults with arthritis suggests the need for increased mental health screening, with subsequent referral to mental health professionals or other treatment programs, in that population.

Keywords: serious psychological distress, anxiety, depression, access to mental health care, rheumatoid arthritis

\section{Introduction}

The prevalence of mental health conditions such as depression, anxiety, and serious psychological distress (SPD; a nonspecific indicator of mental health problems) is higher among adults with arthritis compared to the general population. ${ }^{1-3}$ In individuals with arthritis, mental health issues interact with other health conditions and functional states (e.g., pain, fatigue, and disability ${ }^{4-9}$ ) such that deterioration in one area can directly or indirectly affect the others. Mental health comorbidities in individuals with chronic diseases can exacerbate disability, ${ }^{10,11}$ interfere with disease management, ${ }^{12,13}$ and increase disease severity and mortality. ${ }^{14,15}$ Providing adequate mental health care for these populations is, therefore, an important strategy for improving overall wellbeing. The benefits of doing so have been documented: treating depression can improve medication adherence for chronic conditions, ${ }^{16}$ and interventions to treat mental health issues among individuals with arthritis improve both psychological and physical outcomes. ${ }^{17-20}$ Immune Tolerance Network, I85 Berry Street, Suite 35I5, San Francisco, CA 94107, USA

Tel + I 4I 52780702

Fax + I 4I 52780708

Email laurae.straub@gmail.com 
Access to and use of mental health care services is a challenging public health issue for the US population, where significant unmet need in the treatment of mental health disorders exists. Analysis of data from a nationally representative face-to-face household survey of adults (the World Health Organization's National Comorbidity Survey, carried out in 2001-2003) found $\sim 60 \%$ of US adults with psychological problems did not receive any form of mental health care service in the previous year. ${ }^{21}$ Among the arthritis population specifically, a survey of older osteoarthritis patients with depressed mood assessed prospectively between 1996 and 1998 found that a little less than half received no mental health care, ${ }^{22}$ and the Arthritis Conditions Health Effects Survey reported that only $50 \%$ of participants with anxiety and/or depression sought care for their condition. ${ }^{23}$ Gaps in mental health treatment likely result from multiple factors; frequently cited barriers to receiving mental health care include financial issues, insurance coverage limits, ${ }^{24,25}$ and attitudinal obstacles. ${ }^{26}$

The arthritis literature concerning mental health in this population has been focused on elderly and middle age persons, specifically the prevalence and predictors of mental health conditions, ${ }^{1,2,23}$ and impacts of comorbid mental health conditions on outcomes. ${ }^{14,15}$ To our knowledge, no studies concerning access to mental health care services in the US arthritis population have been published in the past 10 years. In order to treat mental health conditions effectively and reduce relapse in this population, analyses that include younger adults and identify correlates of barriers to mental health care services are needed. To address these gaps, we used data from the 2011 to 2013 National Health Interview Survey (NHIS) to accomplish the following objectives: 1) estimate the prevalence of SPD, depression, and anxiety among US adults with arthritis compared to those without arthritis; 2) among adults with arthritis, characterize individuals with and without SPD and assess the proportion that saw a mental health professional in the past year; and 3) among the subset of adults with both arthritis and SPD, determine characteristics associated with seeing a mental health professional in the past year.

\section{Materials and methods Data source}

The NHIS is an annual, cross-sectional, in-person household survey that uses a multistage, complex sampling design to generate health-status estimates representative of the US civilian noninstitutionalized population. ${ }^{27}$ NHIS survey data are deidentified and publicly available through the Centers for
Disease Control and Prevention's (CDC) website. US Census Bureau interviewers collect data on sociodemographic characteristics, health status, health insurance, and health care utilization for each individual in the household. The sample adult core, which includes measurement of chronic diseases such as arthritis, mental health conditions, and functional and social limitations, is administered to one randomly sampled adult in each household. ${ }^{28}$ We combined data for adults $\geq 18$ years of age in the 2011-2013 sample adult core files to yield a large sample size and stable estimates. The combined file included 102,096 individuals, of which 136 were missing arthritis status. The response rate for the NHIS sample adult module was $81.6 \%$ for $2011,79.7 \%$ for 2012 , and $81.7 \%$ for $2013 .{ }^{29}$ Because respondents tend to answer household income questions at a much lower level than other questionnaire items, the National Center for Health Statistics includes an imputed income file with every annual release. ${ }^{30}$ We use this file for all analyses including income.

\section{Analysis variables}

\section{Mental health conditions}

Individuals were determined to have SPD using the validated Kessler 6 (K6) scale. ${ }^{31,32} \mathrm{~K} 6$ scores are derived from responses to six questions asking how often in the past 30 days the individual felt "nervous", "restless", "hopeless", "worthless", "everything feels like an effort", and "so sad that nothing cheers them up", with responses ranging from 0 (none of the time) to 4 (all of the time). The responses for these six variables are summed to obtain the K6 score (maximum possible score of 24), and individuals with a score of $\geq 13$ are considered to have SPD. ${ }^{31}$ Information for three other mental health conditions including depression ("Have you ever been told by a doctor or other health professional that you had depression?" and "During the past 12 months, have you ever had depression?"), anxiety ("During the past 12 months, have you frequently felt anxious, nervous, or worried?"), and stress ("During the past 12 months, have you frequently felt stressed?") - was collected only in 2012 NHIS.

\section{Arthritis, other chronic conditions, and other health characteristics}

Arthritis status was determined by the question, "Have you ever been told by a doctor or other health professional that you have some form of arthritis, rheumatoid arthritis, gout, lupus, or fibromyalgia?" All of the conditions included in this question are characterized by pain and stiffness in and around the joints. The term "arthritis" is used in the public health sphere as a general term for arthritis and other rheumatic 
conditions of varying severity that affect the joints and tissues surrounding the joints. ${ }^{33}$ Throughout the rest of the paper, "arthritis" is used to describe this group of conditions.

Other chronic conditions were assessed with similar questions. We created a chronic condition count based on the following eight nonarthritis chronic conditions: cancer (except nonmelanoma skin); heart condition (including coronary heart disease, angina, myocardial infarction, or any other heart condition); diabetes; hepatitis or liver condition; hypertension (on at least two different visits); respiratory conditions (current asthma, emphysema, or chronic bronchitis); stroke; and weak or failing kidneys, defined similar to the recommendations of Goodman et al. ${ }^{34}$ We also examined respondent-reported general health status (very good/excellent, good, poor/fair), body mass index $\left(\mathrm{kg} / \mathrm{m}^{2}\right)$ calculated from self-reported height and weight $(<25,25$ to $<30, \geq 30)$, and physical activity levels based on the aerobic activity recommendations for adults in the 2008 Physical Activity Guidelines for Americans. ${ }^{35}$

\section{Sociodemographic characteristics}

We examined age (18-44, 45-64, $\geq 65)$, sex, race/ethnicity (non-Hispanic white, non-Hispanic black, Hispanic, Asian, other), income-to-poverty ratio, that is, household income as a percentage of federal poverty level $(<100 \%, 100$ to $<200 \%$, $\geq 200 \%$ ) (from the imputed income file), ${ }^{30}$ education level (less than high school, high school, some college or associate degree, bachelor's degree or greater), employment status (employed, retired, disabled, unemployed, volunteer/not in labor force), and marital status (married, widowed, divorced/ separated, never married, living with partner).

\section{Functional and social limitations}

We created a functional limitations score by averaging respondent's ratings of their ability to perform nine activities without special equipment (walk a quarter mile; climb 10 steps; stand for 2 hours; sit for 2 hours; stoop, bend, or kneel; reach overhead; grasp small objects; lift/carry 10 pounds; and push large objects) as per previous work. ${ }^{36}$ Responses for each question ranged from "not at all difficult" to "can't do at all" and were assigned numerical values from 0 to 4 , increasing with difficulty. The average score of the responses to all nine activities was grouped as follows to categorize functional limitation: none $(0)$, low ( $>0$ but $<1$ ), medium $(>1$ but $<2$ ), and high $(\geq 2)$. We defined social participation restriction as difficulty or inability to shop, go to events, or participate in social activities without special equipment, per previously published analyses. ${ }^{37}$

\section{Access to care}

Variables related to health care access and utilization were health insurance status (any private, public only, not covered), being able to afford mental health counseling in the past year ("During the past 12 months, was there any time when you needed any of the following but didn't get it because you couldn't afford it? ... Mental health care or counseling"), and seeing a mental health professional in the past 12 months ("During the past 12 months, have you seen or talked to any of the following health care providers about your own health? ...A mental health professional such as a psychiatrist, psychologist, psychiatric nurse, or clinical social worker"').

\section{Data analysis}

Our initial step was to estimate prevalence proportions and 95\% confidence intervals (CIs) of SPD and the other mental health conditions stratified by arthritis status. Then, in the subgroup of adults with arthritis $(n=24,954)$, we compared the distribution of all characteristics described above for adults with SPD $(\mathrm{N}=1,762)$ to adults without (arthritis only, $\mathrm{n}=22,708$ ). In our third step, we investigated correlates of seeing a mental health professional in the past 12 months among adults with arthritis and SPD; that is, among people with arthritis who also had SPD, we estimated associations of the above variables with seeing a mental health professional in the past 12 months.

To develop multivariable logistic regression models predicting the likelihood of seeing a mental health professional in the past 12 months, we first examined univariate logistic regressions for each potential independent variable separately. $P$-values were calculated using the Wald chi-square test. Because age, sex, race, and education affect health care utilization, they were entered in all multivariable models and were retained in the final model regardless of statistical significance. All other variables with unadjusted associations (prevalence ratios [PRs]) that were significant at the $\alpha=0.05$ level were considered for inclusion in a final multivariable model. We screened for multicollinearity among all variables by examining Pearson correlations to identify pairs of independent variables that were more highly correlated with each other than the outcome. In each case, the variable most highly correlated with the outcome (seeing mental health professional in the past year) was chosen for inclusion in the final multivariable model. Because insurance status could modify someone's ability to afford mental health care in the past year, we also evaluated the interaction between these two variables in the final model. 
We applied sampling weights to all analyses in order to create nationally representative estimates. We estimated PRs and 95\% CIs using logistic regression models in SUDAAN 11.0 (Research Triangle Park, NC, USA); ${ }^{38}$ all other analyses were executed using SAS 9.4 SURVEY procedures (Cary, NC, USA $)^{39}$ with Taylor series linearization to account for the NHIS complex sampling design. Observations with missing values were excluded from analyses; however, information from excluded observations was included in variance calculations using the missing at random assumption. ${ }^{40}$

\section{Results}

Table 1 reports the prevalence of SPD and other mental health conditions among adults with and without arthritis. Prevalence of SPD in the past 30 days was almost threefold higher in adults with arthritis compared to those without (6.8\% vs. $2.4 \%$ ). Prevalence proportions for depression (19.4\% vs. $7.3 \%)$, anxiety (29.3\% vs. $16.3 \%)$, and stress (38.0\% vs. $26.4 \%$ ) in the past 12 months were also substantially higher for the arthritis population. Among those with arthritis who reported frequent anxiety, $86 \%$ also reported frequent stress, and $67 \%$ of those reporting frequent stress also reported frequent anxiety (data not shown). The prevalence of adults with arthritis and SPD in the past 30 days in 2011-2013 NHIS was 3.5 million; annual prevalence of depression and frequent anxiety for adults with arthritis in 2012 was 10.0 and 15.2 million, respectively.

Overall, adults with arthritis and SPD were more socially disadvantaged, with more comorbidity and limitation than adults with arthritis only (Table 2). Specifically, statistically significantly higher proportions of those with SPD had less than a high school education (30.0\% vs. $14.5 \%)$, low income-to-poverty ratio ( $36.0 \%$ vs. $11.5 \%)$, work disability ( $54.1 \%$ vs. $13.1 \%$ ), and $\geq 3$ comorbid conditions $(35.8 \%$ vs. $17.7 \%$ ) compared to their counterparts without SPD. In addition, the subset with SPD was less than half as likely to meet the US recommended physical activity guidelines for adults $(17.5 \%$ vs. $39.6 \%)$, about three times more likely to report poor/fair health $(72.1 \%$ vs. $25.5 \%)$, had a high level of functional limitations (53.9\% vs. 15.5\%), and were over four times as likely to experience social participation restriction (38.6\% vs. $8.9 \%)$. The majority of adults with SPD also reported depression, frequent anxiety, and stress in the past 12 months, with proportions that ranged from three to five times higher than those of without SPD (77.2\% vs. 15.5\%, 89.7\% vs. $25.1 \%$, and $93.1 \%$ vs. $34.3 \%$, respectively). Those with SPD were more likely to have no health insurance $(17.4 \%$ vs. $7.9 \%$ ) and to report not being able to afford mental health care in the past 12 months compared to those without SPD $(22.2 \%$ vs. $2.2 \%)$. Among the group who report having no health insurance (17.4\%), a little less than half also report not being able to afford mental health care (data not shown). This group (no health insurance and cannot afford mental health care) comprises $8.2 \%$ of the population with arthritis and SPD.

Table 3 reports unadjusted and adjusted associations with seeing a mental health professional in the past year for adults with arthritis and SPD. (PRs $>1$ indicate increased prevalence of seeing a mental health professional for the level of the characteristic compared to the reference level, whereas PRs $<1$ demonstrate a decreased prevalence.)

In unadjusted analyses, groups most likely to have seen a mental health professional in the past year were: those who were unable to work due to disability or unemployed (vs. employed), never having married or were divorced/separated

Table I Prevalence of mental health conditions among adults with and without arthritis, NHIS 20II-20I3

\begin{tabular}{|c|c|c|c|c|c|c|c|c|c|}
\hline \multirow[t]{2}{*}{ Characteristics } & \multicolumn{4}{|c|}{ Arthritis $(\mathrm{N}=24,954)$} & \multicolumn{4}{|c|}{ No arthritis $(\mathrm{N}=77,006)$} & \multirow[t]{2}{*}{$P$-value** } \\
\hline & $\mathbf{N}$ & Pop N & $\%$ & $95 \% \mathrm{Cl}$ & $\mathbf{N}$ & Pop N & $\%$ & $95 \% \mathrm{Cl}$ & \\
\hline \multicolumn{10}{|l|}{ SPD in past 30 days } \\
\hline No & 22,708 & $48,642,050$ & 93.2 & $92.8-93.7$ & 73,699 & $|73,79|, 379$ & 97.6 & $97.4-97.7$ & $<0.0001$ \\
\hline Yes & $\mathrm{I}, 762$ & $3,534,393$ & 6.8 & $6.3-7.2$ & 2,066 & $4,313,184$ & 2.4 & $2.3-2.6$ & \\
\hline \multicolumn{10}{|l|}{ Depression* } \\
\hline Never & 5,958 & $38,535,357$ & 74.4 & $73.2-75.6$ & 23,146 & $163,055,889$ & 89.2 & $88.7-89.7$ & $<0.000$ I \\
\hline In the past 12 months & 1,718 & $10,027,107$ & 19.4 & $18.2-20.5$ & 2,126 & $13,36 \mid, 485$ & 7.3 & $6.9-7.7$ & \\
\hline Ever, but not in past 12 months & 546 & $3,234,431$ & 6.2 & $5.6-6.9$ & 967 & $6,349,068$ & 3.5 & $3.2-3.8$ & \\
\hline \multicolumn{10}{|c|}{ Frequently anxious, past I 2 months* } \\
\hline No & 5,694 & $36,630,280$ & 70.7 & $69.5-71.9$ & 21,842 & $153,034,188$ & 83.7 & $83.1-84.3$ & $<0.0001$ \\
\hline Yes & 2,531 & $15,175,040$ & 29.3 & $28.1-30.5$ & 4,403 & $29,779,570$ & 16.3 & $15.7-16.9$ & \\
\hline \multicolumn{10}{|c|}{ Frequently stressed, past I 2 months* } \\
\hline No & 5,068 & $32,078,458$ & 62.0 & $60.4-63.5$ & 19,279 & $134,610,635$ & 73.6 & $72.9-74.4$ & $<0.0001$ \\
\hline Yes & 3,154 & $|9,70|, 79 \mid$ & 38.0 & $36.5-39.6$ & 6,961 & $48,173,798$ & 26.4 & $25.6-27.1$ & \\
\hline
\end{tabular}

Notes: *Sample sizes are lower because variable was only assessed in the $2012 \mathrm{NHIS}$, **Wald chi-square test.

Abbreviations: $\mathrm{Cl}$, confidence interval; NHIS, National Health Interview Survey; SPD, serious psychological distress. 
Table 2 Characteristics of adults with arthritis and SPD compared to adults with arthritis only, NHIS 20II-20I3

\begin{tabular}{|c|c|c|c|c|c|}
\hline \multirow[t]{2}{*}{ Characteristics } & \multicolumn{2}{|c|}{ Arthritis and SPD $(\mathrm{N}=\mathrm{I}, 762)$} & \multicolumn{2}{|c|}{ Arthritis and no SPD $(\mathrm{N}=22,708)$} & \multirow[t]{2}{*}{$P$-value** } \\
\hline & $\mathbf{N}(\%)$ & $95 \% \mathrm{Cl}$ & $\mathbf{N}(\%)$ & $95 \% \mathrm{Cl}$ & \\
\hline \multicolumn{6}{|l|}{ Age (years) } \\
\hline $18-44$ & $365(23.8)$ & $21.0-26.5$ & $2,985(\mid 4.8)$ & $14.1-15.5$ & $<0.0001$ \\
\hline $45-64$ & $1,002(56.7)$ & $53.5-59.8$ & $9,544(45.8)$ & $44.9-46.7$ & \\
\hline$\geq 65$ & $395(19.5)$ & $|7|-2 \mid .9$. & $10,179(39.4)$ & $38.5-40.2$ & \\
\hline \multicolumn{6}{|l|}{ Sex } \\
\hline Male & $565(36.3)$ & $33.4-39.2$ & $8,497(40.8)$ & $40.0-41.7$ & 0.005 \\
\hline Female & I, $197(63.7)$ & $60.8-66.6$ & $|4,2| \mid(59.2)$ & $58.3-60.0$ & \\
\hline \multicolumn{6}{|l|}{ Race/ethnicity } \\
\hline White, non-Hispanic & $1,135(73.7)$ & $71.0-76.5$ & I5,959 (77.8) & $77.0-78.7$ & $<0.0001$ \\
\hline Black, non-Hispanic & $276(11.5)$ & $9.6-13.3$ & $3,647(I I . I)$ & $10.4-1 \mid .8$ & \\
\hline Hispanic & $282(11.6)$ & $9.8-13.4$ & $2,164(7.5)$ & $7.0-8.0$ & \\
\hline Asian, non-Hispanic & $36(1.8)$ & $1.1-2.6$ & $688(2.6)$ & $2.3-2.9$ & \\
\hline Other & $33(1.4)$ & $0.8-1.9$ & $250(0.9)$ & $0.7-1.1$ & \\
\hline \multicolumn{6}{|l|}{ Education } \\
\hline Less than high school & $577(30.0)$ & $27.3-32.6$ & $3,972(\mid 4.5)$ & $13.9-|5|$. & $<0.0001$ \\
\hline High school diploma & $525(2.2)$ & $29.1-35.3$ & 6,494 (29.4) & $28.5-30.3$ & \\
\hline Some college or Associates degree & $517(30.1)$ & $27.1-33.1$ & $6,951(31.4)$ & $30.6-32.2$ & \\
\hline College or greater & $135(7.7)$ & $6.2-9.2$ & $5,213(24.8)$ & $23.9-25.7$ & \\
\hline \multicolumn{6}{|l|}{ Income-to-poverty ratio } \\
\hline$<1$ & $75 I(36.0)$ & $32.9-39.1$ & $3,578(11.5)$ & $11.0-12.0$ & $<0.0001$ \\
\hline I to $<2$ & $524(28.8)$ & $26 .|-3| .5$ & $5,144(19.5)$ & $18.8-20.3$ & \\
\hline$\geq 2$ & $486(35.2)$ & $32.0-38.4$ & $13,986(69.0)$ & $68.0-69.9$ & \\
\hline \multicolumn{6}{|l|}{ Employment/work status } \\
\hline Employed & $3 \mid 4(8.1)$ & $15.7-20.5$ & $8,622(42.0)$ & $4 I .1-43.0$ & $<0.0001$ \\
\hline Retired & $257(14.3)$ & $12.1-16.5$ & $8,807(35.2)$ & $34.3-36.1$ & \\
\hline Disabled & $943(54.1)$ & $50.7-57.5$ & $3,247(13.1)$ & $12.5-13.7$ & \\
\hline Unemployed & $135(7.4)$ & $5.8-8.9$ & $772(3.4)$ & $3.1-3.7$ & \\
\hline Volunteer/NILF & $113(6.1)$ & $4.8-7.5$ & $\mathrm{I}, 247(6.2)$ & $5.8-6.7$ & \\
\hline \multicolumn{6}{|l|}{ Marital status } \\
\hline Married & $530(4 I .5)$ & $38.3-44.8$ & $10,035(58.6)$ & $57.7-59.5$ & $<0.0001$ \\
\hline Widowed & $257(1 \mathrm{I} .2)$ & $9.4-13.0$ & $4,517(13.6)$ & $13.1-14 . \mid$ & \\
\hline Divorced/separated & $604(26.8)$ & $24.1-29.5$ & $4,845(15.0)$ & $14.4-15.5$ & \\
\hline Never married & $269(12.6)$ & $10.8-14.4$ & $2,473(8.4)$ & $7.9-8.8$ & \\
\hline Living with partner & $98(7.9)$ & $6.0-9.7$ & $795(4.5)$ & $4.1-4.8$ & \\
\hline \multicolumn{6}{|l|}{ Comorbid condition count } \\
\hline 0 & $265(16.0)$ & $13.8-18.3$ & 6,07I (29.1) & $28.3-29.9$ & $<0.0001$ \\
\hline I & $406(25.5)$ & $22.8-28.3$ & $7,035(31.6)$ & $30.9-32.3$ & \\
\hline 2 & $423(22.7)$ & $20.3-25.1$ & $5,147(21.6)$ & $21.0-22.3$ & \\
\hline$\geq 3$ & $667(35.8)$ & $32.8-38.7$ & $4,455(17.7)$ & $17.1-18.3$ & \\
\hline \multicolumn{6}{|l|}{ Body mass index (BMI) } \\
\hline Under and normal weight $(<25)$ & $476(28.3)$ & $25.5-31.2$ & $5,847(26.0)$ & $25.2-26.8$ & $<0.0001$ \\
\hline Overweight $(25$ to $<30)$ & $470(27.3)$ & $24.8-29.9$ & $7,608(35.1)$ & $34.3-35.9$ & \\
\hline Obese $(\geq 30)$ & 77 I (44.4) & $41.4-47.4$ & $8,521(38.9)$ & $38.1-39.7$ & \\
\hline \multicolumn{6}{|l|}{ Physical activity } \\
\hline Does not meet recommendations & $\mathrm{I}, 428(82.5)$ & $80.3-84.7$ & 13,963 (60.4) & $59.4-61.4$ & $<0.0001$ \\
\hline Meets recommendations & $304(17.5)$ & $15.3-19.7$ & $8,356(39.6)$ & $38.6-40.6$ & \\
\hline \multicolumn{6}{|l|}{ Self-reported health } \\
\hline Poor/fair & $\mathrm{I}, 287(72.1)$ & $69.4-74.8$ & $6,35 \mathrm{I}(25.5)$ & $24.7-26.3$ & $<0.0001$ \\
\hline Good & $338(19.5)$ & $|7.2-2| .8$ & $7,685(33.5)$ & $32.7-34.3$ & \\
\hline Very good/excellent & $136(8.4)$ & $6.7-10.0$ & $8,658(41.0)$ & $40.1-41.9$ & \\
\hline \multicolumn{6}{|l|}{ Functional limitations } \\
\hline None & $89(5.5)$ & $4.1-7.0$ & $5,969(28.6)$ & $27.8-29.4$ & $<0.0001$ \\
\hline Low & $27 \mid(17.3)$ & $14.8-19.8$ & $8,347(38.4)$ & $37.5-39.2$ & \\
\hline Medium & $433(23.3)$ & $20.5-26.1$ & $4,250(17.5)$ & $16.9-18.1$ & \\
\hline High & $964(53.9)$ & $50.3-57.4$ & $4,097(15.5)$ & $15.0-16.1$ & \\
\hline
\end{tabular}


Table 2 (Continued)

\begin{tabular}{|c|c|c|c|c|c|}
\hline \multirow[t]{2}{*}{ Characteristics } & \multicolumn{2}{|c|}{ Arthritis and SPD $(\mathrm{N}=\mathrm{I}, 762)$} & \multicolumn{2}{|c|}{ Arthritis and no SPD $(\mathrm{N}=22,708)$} & \multirow[t]{2}{*}{$P$-value** } \\
\hline & $\mathbf{N}(\%)$ & $95 \% \mathrm{Cl}$ & $\mathbf{N}(\%)$ & $95 \% \mathrm{Cl}$ & \\
\hline \multicolumn{6}{|l|}{ Social participation restriction } \\
\hline No & $1,080(61.4)$ & $58.0-64.7$ & $20,359(91.1)$ & $90.7-91.6$ & $<0.0001$ \\
\hline Yes & $680(38.6)$ & $35.3-42.0$ & $2,327(8.9)$ & $8.4-9.3$ & \\
\hline \multicolumn{6}{|l|}{ Depression* } \\
\hline Never & $91(18.7)$ & $13.6-23.7$ & $5,813(78.1)$ & $77.0-79.3$ & $<0.000$ I \\
\hline In the past 12 months & $398(77.2)$ & $71.8-82.6$ & $\mathrm{I}, 297(15.5)$ & $14.4-16.5$ & \\
\hline Ever, but not in past 12 months & $25(4.1)$ & $2.2-6.0$ & $519(6.4)$ & $5.7-7.1$ & \\
\hline \multicolumn{6}{|c|}{ Frequently anxious, past 12 months* } \\
\hline No & $49(10.3)$ & $5.9-14.7$ & $5,608(74.9)$ & 73.7-76.I & $<0.0001$ \\
\hline Yes & $465(89.7)$ & $85.3-94.1$ & $2,026(25.1)$ & $23.9-26.3$ & \\
\hline \multicolumn{6}{|c|}{ Frequently stressed, past 12 months* } \\
\hline No & $37(6.9)$ & $2.9-10.9$ & $4,995(65.7)$ & $64.1-67.2$ & $<0.0001$ \\
\hline Yes & $477(93.1)$ & $89.1-97.1$ & $2,638(34.3)$ & $32.8-35.9$ & \\
\hline \multicolumn{6}{|l|}{ Health insurance } \\
\hline Any private & $473(30.5)$ & $27.6-33.5$ & $12,8 \mid 3(6 \mid .5)$ & $60.5-62.4$ & $<0.0001$ \\
\hline Public only & $993(52.0)$ & $48.9-55.2$ & $8,050(30.6)$ & $29.8-31.5$ & \\
\hline Not covered & $290(17.4)$ & $15.1-19.7$ & $1,800(7.9)$ & 7.4-8.4 & \\
\hline \multicolumn{6}{|c|}{ Could not afford mental health care, past 12 months } \\
\hline No & $\mathrm{I}, 389(77.8)$ & $75.2-80.5$ & $22,070(97.8)$ & $97.6-98.1$ & $<0.000$ I \\
\hline Yes & $360(22.2)$ & $19.5-24.8$ & $504(2.2)$ & $1.9-2.4$ & \\
\hline \multicolumn{6}{|c|}{ Seen a mental health professional, past 12 months } \\
\hline No & $1,058(60.8)$ & $57.6-64.0$ & $20,449(91.0)$ & $90.5-91.4$ & $<0.0001$ \\
\hline Yes & $68 I(39.2)$ & $36.0-42.4$ & $2,093(9.0)$ & $8.6-9.5$ & \\
\hline
\end{tabular}

Notes: *Sample sizes are lower because variable was only assessed in the $2012 \mathrm{NHIS}$, *Wald chi-square test. All relative standard errors $<0.25$.

Abbreviations: $\mathrm{Cl}$, confidence interval; NHIS, National Health Interview Survey; SPD, serious psychological distress; NILF, not in labor force.

(vs. married), having public only health insurance (vs. any private), reported poor/fair health (vs. very good/excellent), and who reported not being able to afford mental health care or counseling. Conversely, those who were older (vs. $<45$ years), had less than high school education or no additional education beyond high school (vs. college or greater), identified as Asian (vs. non-Hispanic white), or were widowed (vs. married) were less likely to have seen a mental health care professional in the past year (Table 3 for PRs).

The final multivariable model contained the following covariates: age, sex, race, education, employment, insurance, and inability to afford mental health care at any time in the past 12 months. In that model, groups most likely to have seen a mental health professional in the past year were those unable to work due to disability (vs. employed; $\mathrm{PR}=1.6,95 \% \mathrm{CI}=1.3-2.1$ ) or the unemployed (vs. employed; $\mathrm{PR}=1.5,95 \% \mathrm{CI}=1.1-2.1$ ), and people who reported not being able to afford mental health care in the past 12 months (vs. being able to afford; $P R=1.3$, $95 \% \mathrm{CI}=1.1-1.6$ ). Conversely, those who were older (vs. $<45$ years; $45-64 \mathrm{PR}=0.8,95 \% \mathrm{CI}=0.7-0.9 ; \geq 65 \mathrm{PR}=0.4$, 95\% CI $=0.3-0.6$ ), had less than high school education (vs. college or greater; $\mathrm{PR}=0.5,95 \% \mathrm{CI}=0.4-0.7$ ) or no additional education beyond high school (vs. college or greater; $\mathrm{PR}=0.7,95 \% \mathrm{CI}=0.6-0.9$ ), and those with no health insurance (vs. private; $\mathrm{PR}=0.7,95 \% \mathrm{CI}=0.5-0.8$ ) were less likely to have seen a mental health care professional in the past year. Asian race/ethnicity (vs. White) was no longer statistically significant in the final model.

The interaction between insurance status and ability to afford mental health care in the past year was not significant when added to the final model (data not shown). We, therefore, did not include the interaction term in the adjusted model and did not present stratified results.

\section{Discussion}

Our analysis of nationally representative data estimated that $6.8 \%$ of adults with arthritis had SPD - a prevalence proportion almost three times higher than for adults without arthritis. We also found that the 3.5 million adults with arthritis and SPD were more socially disadvantaged, with more comorbidity and limitation, than adults with arthritis only. Six in 10 of adults with arthritis and SPD did not see a mental health care provider in the past year. Older age, lower levels of education, being employed (compared to being disabled or unemployed), and not having health insurance were associated with not seeing a mental health care professional in the past year when controlling for other variables.

The higher proportions of SPD, anxiety, and depression that we found in adults with arthritis when compared to those 
Table 3 Unadjusted and adjusted associations of respondent characteristics with seeing a mental health care provider in the past 12 months among adults with arthritis and SPD in the past 30 days, NHIS $201 \mathrm{I}-2013$

\begin{tabular}{|c|c|c|c|c|c|c|c|}
\hline \multirow[t]{2}{*}{ Characteristics } & \multicolumn{4}{|c|}{ Unadjusted } & \multicolumn{3}{|c|}{$\begin{array}{l}\text { Final adjusted model } \\
(\mathrm{N}=1,727)\end{array}$} \\
\hline & $\mathbf{N}$ & PR & $95 \% \mathrm{Cl}$ & $P$-value** & PR & $95 \% \mathrm{Cl}$ & $\boldsymbol{P}$-value** \\
\hline Age (vs. I8-44) & 1,739 & & & & & & \\
\hline $45-64$ & & 0.8 & $0.7-1.0$ & $<0.0001$ & 0.8 & $0.7-0.9$ & $<0.0001$ \\
\hline$\geq 65$ & & 0.4 & $0.3-0.5$ & & 0.4 & $0.3-0.6$ & \\
\hline Female (vs. male) & 1,739 & 1.0 & $0.9-1.2$ & 0.78 & I.I & $0.9-1.3$ & 0.40 \\
\hline Race/ethnicity (vs. White, non-Hispanic) & $\mathrm{I}, 739$ & & & & & & \\
\hline Black, non-Hispanic & & 0.9 & $0.7-1.1$ & 0.06 & 0.8 & $0.7-1.0$ & 0.06 \\
\hline Hispanic & & 0.9 & $0.7-1.1$ & & 1.0 & $0.9-1.3$ & \\
\hline Asian, non-Hispanic & & 0.3 & $0.1-0.8$ & & 0.3 & $0.1-1.1$ & \\
\hline Other & & 1.0 & $0.6-1.6$ & & 0.9 & $0.6-1.5$ & \\
\hline Highest education (vs. college or greater) & $\mathrm{I}, 732$ & & & & & & \\
\hline Less than high school & & 0.6 & $0.4-0.8$ & $<0.0001$ & 0.5 & $0.4-0.7$ & $<0.000$ I \\
\hline High school diploma & & 0.8 & $0.6-1.0$ & & 0.7 & $0.6-0.9$ & \\
\hline Some college or associates degree & & 0.9 & $0.7-1.2$ & & 0.8 & $0.7-1.0$ & \\
\hline Income-to-poverty ratio* (vs. $\geq 2$ ) & $\mathrm{I}, 739$ & & & 0.99 & & & \\
\hline$<1$ & & 1.0 & $0.8-1.2$ & & & & \\
\hline I to $<2$ & & 1.0 & $0.8-1.2$ & & & & \\
\hline Employment status (vs. employed) & 1,739 & & & & & & \\
\hline Retired & & 0.7 & $0.5-1.0$ & $<0.0001$ & 1.3 & $0.9-1.9$ & $<0.0001$ \\
\hline Disabled & & 1.5 & $1.2-1.9$ & & 1.6 & $1.3-2.1$ & \\
\hline Unemployed & & 1.5 & $1.1-2.1$ & & 1.5 & $1.1-2.1$ & \\
\hline Volunteer/NILF & & 0.8 & $0.5-1.3$ & & 0.8 & $0.5-1.3$ & \\
\hline Marital status (vs. married) & $\mathrm{I}, 735$ & & & & & & \\
\hline Widowed & & 0.7 & $0.5-0.9$ & 0.0003 & & & \\
\hline Divorced/separated & & 1.2 & $1.0-1.4$ & & & & \\
\hline Never married & & $\mathrm{I} .4$ & $1.1-1.7$ & & & & \\
\hline Living with partner & & 1.0 & $0.8-1.4$ & & & & \\
\hline Comorbid condition count (vs. none) & $\mathrm{I}, 738$ & & & & & & \\
\hline 1 & & I.I & $0.9-1.4$ & 0.40 & & & \\
\hline 2 & & 0.9 & $0.7-1.2$ & & & & \\
\hline $3+$ & & 1.0 & $0.8-1.2$ & & & & \\
\hline BMI (vs. <25) & $\mathrm{I}, 702$ & & & & & & \\
\hline Overweight ( 25 to $<30)$ & & 1.0 & $0.8-1.2$ & 0.58 & & & \\
\hline Obese $(\geq 30)$ & & I.I & $0.9-1.3$ & & & & \\
\hline $\begin{array}{l}\text { Does not meet physical activity recommendations } \\
\text { (vs. meets recommendations) }\end{array}$ & I,717 & 0.9 & $0.8-1.2$ & 0.56 & & & \\
\hline Self-rated general health (vs. very good/excellent) & 1,738 & & & & & & \\
\hline Good & & I.I & $0.8-1.6$ & 0.036 & & & \\
\hline Poor/fair & & 1.3 & $1.0-1.8$ & & & & \\
\hline Functional limitations (vs. none) & 1,736 & & & & & & \\
\hline Low & & 0.7 & $0.5-1.1$ & 0.12 & & & \\
\hline Medium & & 1.0 & $0.7-1.4$ & & & & \\
\hline High & & 0.9 & $0.6-1.2$ & & & & \\
\hline Social participation restriction (vs. no) & 1,739 & 1.0 & $0.8-1.2$ & 0.96 & & & \\
\hline Health insurance (vs. any private) & $\mathrm{I}, 733$ & & & & & & \\
\hline Public only & & 1.2 & $1.0-1.5$ & 0.0025 & 1.1 & $0.9-1.4$ & 0.0001 \\
\hline Not covered & & 0.8 & $0.6-1.1$ & & 0.7 & $0.5-0.8$ & \\
\hline $\begin{array}{l}\text { Could not afford mental health care, past } 12 \text { months } \\
\text { (vs. could) }\end{array}$ & I,739 & 1.4 & $1.2-1.7$ & 0.0003 & 1.3 & $1.1-1.6$ & 0.017 \\
\hline
\end{tabular}

Notes: *Missing values imputed by survey staff, **Wald chi-square test.

Abbreviations: BMI, body mass index; CI, confidence interval; NHIS, National Health Interview Survey; PR, prevalence ratio; SPD, serious psychological distress.

without arthritis are consistent with previous findings. Using 2002 NHIS, Shih et al estimated a prevalence proportion for SPD of $5.6 \%(\mathrm{CI}=5.0 \%-6.3 \%){ }^{1}$ This is slightly lower than the prevalence proportion $(6.8 \%$; $\mathrm{CI}=6.3 \%-7.2 \%)$ we found in 2011-2013. An analysis of the Arthritis Conditions Health Effects Survey - a nationally representative sample 
of US adults ages $\geq 45$ self-reporting arthritis or chronic joint symptoms in 2005 and 2006 - estimated prevalence proportions for anxiety and depression at $30.5 \%$ and $17.5 \%$, respectively, among adults with arthritis. ${ }^{23}$ And although that study used validated arthritis-specific instruments to identify those conditions whereas our analysis used the single questions available in 2012 NHIS, those estimates are very similar to our NHIS 2012 estimates (29.3\% and 19.4\%).

Our results suggest an unmet need for mental health care services in the population with arthritis and SPD and confirm findings from other studies that insurance coverage is an important barrier to mental health care. ${ }^{41}$ Because treating depression in individuals with arthritis can improve outcomes, ${ }^{19}$ screening for anxiety and depression in arthritis patients should be routine, ${ }^{23}$ particularly if patients are unlikely to bring up mental health concerns with providers on their own. ${ }^{42,43}$

Income was not associated with seeing a mental health care professional in the past year, an indication that health insurance or other nonfinancial barriers may play a larger role in receiving care. For example, stigmas about mental illness ${ }^{42}$ or the belief that mental health problems can be overcome on their own ${ }^{26,42}$ have been identified as significant barriers to treatment. And while those of Asian race/ethnicity were less likely to receive mental health care in the past year (vs. White, non-Hispanic), this association was of borderline statistical significance in the final adjusted model $(\mathrm{PR}=0.3$, $95 \% \mathrm{CI}=0.1-1.1$ ), but is consistent with other reports that stigmatization of mental health conditions may be particularly important in this population. ${ }^{44,45}$ Lack of continuity of care with primary health care providers has also been reported as a hindrance to establishing the comfort level needed for patients to initiate conversations about mental health problems. ${ }^{42}$ These nonfinancial barriers were not measured in NHIS but could provide further explanation for not receiving care and highlight the importance of addressing both financial and nonfinancial barriers to care.

One seemingly counter-intuitive finding, among those with arthritis and SPD, not being able to afford mental health care at some point in the past year was also associated with seeing a mental health professional $(\mathrm{PR}=1.3 ; 95 \% \mathrm{CI}=1.1-$ 1.6). This may indicate that although these individuals were able to see a mental health care professional in the past year, they may not be getting the full extent of care required. This would be consistent with findings from one survey-based study reporting that $26 \%$ of adults with self-reported arthritis who had difficulty receiving mental health care services cited "limits on the number of visits" as the reason for not obtaining care. ${ }^{26}$ Cost of care is an important health policy challenge, and strategies such as community-based chronic disease self-management programs (CDSMPs) should be considered as potential low-cost option to improve the mental health of adults with arthritis, particularly because CDSMPs have demonstrated the ability to improve both physical and psychological health in individuals with chronic disease. ${ }^{46}$ Another low-cost approach to improve physical and psychological health among adults with arthritis is walking programs (e.g., Walk with Ease). In controlled trials of walking programs, adults with arthritis have demonstrated decreased pain and depression and increased mobility and physical performance. ${ }^{47}$

Our study includes several important limitations. First of all, arthritis status was based on self-report and, therefore, subject to misclassification; however, this question has demonstrated a high positive predictive value in a clinic-based validation study. ${ }^{48}$ Because NHIS data are cross-sectional, we could not investigate causality between seeing a mental health care provider in the past year and the correlates we identified. As mentioned in the "Materials and methods" section, arthritis status was determined by a question that also includes other rheumatic and joint disorders (gout, lupus, fibromyalgia), and there may be differences in the prevalence of SPD or access to mental health care services for these different disorders that unfortunately cannot be ascertained from this survey data. Finally, although one of our objectives was to assess the unmet need for mental health care among adults with arthritis and SPD, we could only examine a proxy measure, having seen a mental health care provider in the past year. Strengths of this analysis include use of an up-to-date sample of nationally representative adults and a validated instrument to identify SPD.

Because mental health conditions, such as anxiety and depression, and severe manifestations of these conditions, such as SPD in particular, can exacerbate arthritis-related pain, fatigue, and disability, identifying these conditions in adults with arthritis is an important priority in primary care. Subsequent referral of these individuals to a mental health care provider or other mental health treatment programs may help satisfy the unmet need for treatment. While barriers to mental health treatment due to lack of insurance or insufficient mental health benefits will need to be addressed at a policy level, lower cost interventions such as CDSMPs may serve as alternative strategies to improve mental health in individuals with barriers to mental health treatment, as well as for individuals who may be reluctant to see a mental health care provider.

\section{Acknowledgments}

We thank Dr. Louise Murphy and Dr. Theresa Brady at the Centers for Disease Control and Prevention (CDC) for their advice and feedback on this manuscript. 


\section{Disclosure}

Cisternas' work on this project was supported by contracts from the Centers for Disease Control and Prevention (contract number 200-2013-M-56817). Straub reports no conflicts of interest in this work.

\section{References}

1. Shih M, Hootman JM, Strine TW, Chapman DP, Brady TJ. Serious psychological distress in U.S. adults with arthritis. J Gen Intern Med. 2006; 21(11):1160-1166.

2. Isik A, Koca SS, Ozturk A, Mermi O. Anxiety and depression in patients with rheumatoid arthritis. Clin Rheumatol. 2007;26(6):872-878.

3. Stang PE, Brandenburg NA, Lane MC, Merikangas KR, Von Korff MR, Kessler RC. Mental and physical comorbid conditions and days in role among persons with arthritis. Psychosom Med. 2006;68(1):152-158.

4. Hawker GA, Gignac MA, Badley E, et al. A longitudinal study to explain the pain-depression link in older adults with osteoarthritis. Arthritis Care Res (Hoboken). 2011;63(10):1382-1390.

5. Bacconnier L, Rincheval N, Flipo RM, et al. Psychological distress over time in early rheumatoid arthritis: results from a longitudinal study in an early arthritis cohort. Rheumatology. 2015;54(3):520-527.

6. Kojima M, Kojima T, Suzuki S, et al. Depression, inflammation, and pain in patients with rheumatoid arthritis. Arthritis Rheum. 2009;61(8):1018-1024.

7. Overman CL, Bossema ER, van Middendorp H, et al. The prospective association between psychological distress and disease activity in rheumatoid arthritis: a multilevel regression analysis. Ann Rheum Dis. 2012; 71(2):192-197.

8. Wolfe F, Michaud K. Predicting depression in rheumatoid arthritis: the signal importance of pain extent and fatigue, and comorbidity. Arthritis Rheum. 2009;61(5):667-673.

9. Odegard S, Finset A, Mowinckel P, Kvien TK, Uhlig T. Pain and psychological health status over a 10-year period in patients with recent onset rheumatoid arthritis. Ann Rheum Dis. 2007;66(9):1195-1201.

10. Lowe B, Willand L, Eich W, et al. Psychiatric comorbidity and work disability in patients with inflammatory rheumatic diseases. Psychosom Med. 2004;66(3):395-402.

11. Karpouzas GA, Dolatabad S, Moran R, Li N, Nicassio PM, Weisman MH. Correlates and predictors of disability in vulnerable US Hispanics with rheumatoid arthritis. Arthritis Care Res (Hoboken). 2012; 64(9):1274-1281.

12. DiMatteo MR, Lepper HS, Croghan TW. Depression is a risk factor for noncompliance with medical treatment: meta-analysis of the effects of anxiety and depression on patient adherence. Arch Intern Med. 2000;160(14):2101-2107.

13. Cabrera-Marroquin R, Contreras-Yanez I, Alcocer-Castillejos N, Pascual-Ramos V. Major depressive episodes are associated with poor concordance with therapy in rheumatoid arthritis patients: the impact on disease outcomes. Clin Exp Rheumatol. 2014;32(6):904-913.

14. Ang DC, Choi H, Kroenke K, Wolfe F. Comorbid depression is an independent risk factor for mortality in patients with rheumatoid arthritis. J Rheumatol. 2005;32(6):1013-1019.

15. Godha D, Shi L, Mavronicolas H. Association between tendency towards depression and severity of rheumatoid arthritis from a national representative sample: the Medical Expenditure Panel Survey. Curr Med Res Opin. 2010;26(7):1685-1690.

16. Katon W, Cantrell CR, Sokol MC, Chiao E, Gdovin JM. Impact of antidepressant drug adherence on comorbid medication use and resource utilization. Arch Intern Med. 2005;165(21):2497-2503.

17. Sharpe L, Sensky T, Timberlake N, Ryan B, Allard S. Long-term efficacy of a cognitive behavioural treatment from a randomized controlled trial for patients recently diagnosed with rheumatoid arthritis. Rheumatology. 2003;42(3):435-441.

18. Parker JC, Smarr KL, Slaughter JR, et al. Management of depression in rheumatoid arthritis: a combined pharmacologic and cognitivebehavioral approach. Arthritis Rheum. 2003;49(6):766-777.
19. Lin EH, Katon W, Vom Korff M, et al. Effect of improving depression care on pain and functional outcomes among older adults with arthritis: a randomized controlled trial. JAMA. 2003;290(18): 2428-2429.

20. Astin JA, Beckner W, Soeken K, Hochberg MC, Berman B. Psychological interventions for rheumatoid arthritis: a meta-analysis of randomized controlled trials. Arthritis Rheum. 2002;47(3):291-302.

21. Wang PS, Lane M, Olfson M, Pincus HA, Wells KB, Kessler RC. Twelve-month use of mental health services in the United States: results from the National Comorbidity Survey Replication. Arch Gen Psychiatry. 2005;62(6):629-640.

22. Gleicher Y, Croxford R, Hochman J, Hawker G. A prospective study of mental health care for comorbid depressed mood in older adults with painful osteoarthritis. BMC Psychiatry. 2011;11:147.

23. Murphy LB, Sacks JJ, Brady TJ, Hootman JM, Chapman DP. Anxiety and depression among US adults with arthritis: prevalence and correlates. Arthritis Care Res (Hoboken). 2012;64(7):968-976.

24. Sareen J, Jagdeo A, Cox BJ, et al. Perceived barriers to mental health service utilization in the United States, Ontario, and the Netherlands. Psychiatr Serv. 2007;58(3):357-364.

25. Mojtabai R. Trends in contacts with mental health professionals and cost barriers to mental health care among adults with significant psychological distress in the United States: 1997-2002. Am J Public Health. 2005;95(11):2009-2014.

26. Hagglund KJ, Clark MJ, Hilton SA, Hewett JE. Access to healthcare services among persons with osteoarthritis and rheumatoid arthritis. Am J Phys Med Rehabil. 2005;84(9):702-711.

27. National Center for Health Statistics. National Health Interview Survey. Available from: http://www.cdc.gov/nchs/nhis.htm. Accesssed April 2015.

28. National Center for Health Statistics. Survey Description, National Health Interview Survey, 2011-2013. Public use datafile and documentation. Available from: http://www.cdc.gov/nchs.nhis.htm. Accessed April 2015.

29. National Center for Health Statistics. Survey Description, National Health Interview Survey, 2013. Hyattsville, MD; 2014.

30. National Center for Health Statistics. 2010 Imputed Family Income/ Personal Earnings Files. Public-use datafile and documentation. Available from: http://www.cdc.gov/nchs/nhis/2010imputedincome.htm. Accessed April 2015.

31. Kessler RC, Andrews G, Colpe LJ, et al. Short screening scales to monitor population prevalences and trends in non-specific psychological distress. Psychol Med. 2002;32(6):959-976.

32. Kessler RC, Barker PR, Colpe LJ, et al. Screening for serious mental illness in the general population. Arch Gen Psychiatry. 2003;60(2): 184-189.

33. Centers for Disease Control and Prevention. Frequently Asked Questions (FAQs) - Arthritis. Available from: https://www.cdc.gov/arthritis/basics/ faqs.htm. Accessed December 1, 2016.

34. Goodman RA, Posner SF, Huang ES, Parekh AK, Koh HK. Defining and measuring chronic conditions: imperatives for research, policy, program, and practice. Prev Chronic Dis. 2013;10:E66.

35. US Department of Health and Human Services. 2008 Physical Activity Guidelines for Americans. Available from: http://health.gov/paguidelines/pdf/paguide/pdf. Accessed April 2015.

36. Murphy LB, Yelin E, Theis KA. Compromised access to prescriptions and medical care because of cost among US adults with arthritis. Best Pract Res Clin Rheumatol. 2012;26(5):677-694.

37. Theis KA, Murphy L, Hootman JM, Wilkie R. Social participation restriction among US adults with arthritis: a population-based study using the International Classification of Functioning, Disability and Health. Arthritis Care Res. 2013;65(7):1059-1069.

38. Research Triangle Institute. SUDAAN Language Manual, Release 11.0. Research Triangle Park, NC: Research Triangle Institute; 2012.

39. SAS Institute Inc. 2014. SAS/STAT® 13.2 User's Guide. Cary, NC: SAS Institute Inc.

40. Allison PD. Quantitative Applications in the Social Sciences. Thousand Oaks, CA: Sage Publications; 2001. 
41. Rowan K, McAlpin DD, Blewett LA. Access and cost barriers to mental health care, by insurance status, 1999-2010. Health Aff. 2013; 32(10):1723-1730.

42. Withers M, Moran R, Nicassio P, Weisman MH, Karpouzas GA. Perspectives of vulnerable US Hispanics with rheumatoid arthritis on depression: awareness, barriers to disclosure, and treatment options. Arthritis Care Res. 2015;67(4):484-492.

43. Sleath B, Chewning B, de Vellis BM, et al. Communication about depression during rheumatoid arthritis patient visits. Arthritis Rheum. 2008; 59(2):186-191.

44. Sorkin DH, Nguyen H, Ngo-Metzger Q. Assessing the mental health needs and barriers to care among a diverse sample of Asian American older adults. J Gen Intern Med. 2011;26(6):595-602.
45. Rastogi P, Khushalani S, Dhawan S, et al. Understanding clinician perception of common presentations in South Asians seeking mental health treatment and determining barriers and facilitators to treatment. Asian J Psychiatr. 2014;7(1):15-21.

46. Brady TJ, Murphy L, O'Colmain BJ, et al. A meta-analysis of health status, health behaviors, and healthcare utilization outcomes of the Chronic Disease Self-Management Program. Prev Chronic Dis. 2013;10:120112.

47. Bruno M, Cummins S, Gaudiano L, Stoos J, Blanpied P. Effectiveness of two arthritis foundation programs: walk with ease, and YOU can break the pain cycle. Clin Interv Aging. 2006;1(3):295-306.

48. Sacks JJ, Harrold LR, Helmick CG, Gurwitz JH, Emani S, Yood RA. Validation of a surveillance case definition for arthritis. JRheumatol. 2005; 32(2):340-347.

\section{Publish your work in this journal}

Open Access Rheumatology: Research and Reviews is an international, peerreviewed, open access journal publishing original research, reports, editorials, reviews and commentaries on all aspects of clinical and experimental rheumatology in the clinic and laboratory including the following topics: Pathology, pathophysiology of rheumatological diseases; Investigation, treatment and management of rheumatological diseases; Clinical trials and novel pharmacological approaches for the treatment of rheumatological disorders. The manuscript management system is completely online and includes a very quick and fair peer-review system, which is all easy to use. Visit http://www.dovepress.com/ testimonials.php to read real quotes from published authors. 